\title{
Structure of iron nitrides under different nitridation temperatures
}

\author{
Shuai $\mathrm{Ye}^{1, \mathrm{a}}$ and Yujie $\mathrm{Cao}^{2, \mathrm{~b}}$ \\ College of Electronic Science and Engineering, Nanjing University of Posts and \\ Telecommunications, Nanjing, China, 210046 \\ ab13020114@njupt.edu.cn, ${ }^{\mathrm{b} b 13020110 @ n j u p t . e d u . c n}$
}

Keywords: iron nitride, sol-gel method, XRD.

\begin{abstract}
Using the method of sol-gel and high-temperature nitridation, we prepared iron nitride compounds. Recently, iron nitrides have been achieving more attention due to their excellent magnetic properties. Using X-ray diffraction technique, the crystal structure has been investigated. It is found that, when the nitridation temperature is lower, the achieved samples are composed of multi-phases, which contained $\mathrm{Fe}-\mathrm{O}$ and $\mathrm{Fe}-\mathrm{N}$ compounds. Increasing the nitridation temperature to $850^{\circ} \mathrm{C}$, single phase $\varepsilon-\mathrm{Fe}_{3} \mathrm{~N}$ has been observed.
\end{abstract}

\section{Introduction}

Known as a kind of traditional magnetic materials, iron nitrides have been attracting wide attention. In the early 1950s, researchers began the systematic study of iron nitrides like $\mathrm{Fe}_{3} \mathrm{~N}, \mathrm{Fe}_{4} \mathrm{~N}$ etc. [1]. In recent years, the iron nitride compounds have gained growing interest due to their extraordinary properties such as antioxidant, anti-abrasion and anticorrosion, especially the complex magnetic properties. For iron nitrides fabricated by different methods, the proportion of Fe: $\mathrm{N}$ can be different and besides, the microstructural, magnetic and electronic properties also vary. According to the different proportion of iron to nitrogen, iron nitrides can be divided into several kinds: $\mathrm{Fe}_{2} \mathrm{~N}, \mathrm{Fe}_{3} \mathrm{~N}$, $\mathrm{Fe}_{4} \mathrm{~N}, \mathrm{Fe}_{16} \mathrm{~N}_{2}$ [2] etc.

In this paper, we prepared the iron nitrides samples by sol-gel method and high-temperature nitridation method, and the structural characteristics have been investigated.

\section{Properties of iron, iron oxide and iron nitride}

Based on the results we have got, it is found that the samples we prepared would contain iron, iron oxide and different kinds of iron nitrides.

Single crystalline iron has at least four different crystal structures, known as $\alpha, \gamma, \delta$, and $\varepsilon$. Both $\alpha$-iron (Fig. 1(a)) and $\delta$-iron (Fig. 1(c)) have a body-centered cubic (bcc) crystal structure. While $\gamma$-iron, as shown in Fig. 1(b), has a face-centered cubic (fcc) crystal structure. $\alpha$-iron is usually achieved under ordinary conditions, and at pressures above approximately $10 \mathrm{GPa}$ and temperatures of a few hundred kelvin or less, $\alpha$-iron will change into a hexagonal close-packed (hcp) structure, which is also known as $\varepsilon$-iron (Fig. 1(d)) [3].

Fig. 2 present the crystal structures of $\mathrm{FeN}, \mathrm{Fe}_{2} \mathrm{~N}, \mathrm{Fe}_{2 \sim 3} \mathrm{~N}$ and $\mathrm{Fe}_{4} \mathrm{~N}$ [4,6]. As typical ferromagnetic materials, $\mathrm{Fe}_{2 \sim 3} \mathrm{~N}$ and $\mathrm{Fe}_{4} \mathrm{~N}$ got more attention [7]. The crystal structure of $\varepsilon-\mathrm{Fe}_{3} \mathrm{~N}$ is shown in Fig. 2(c). $\varepsilon-\mathrm{Fe}_{3} \mathrm{~N}$ phase has the rhombohedral structure, the lattice constant of which is about $a=0.466 \mathrm{~nm}$ and $c=0.436 \mathrm{~nm}$. At the condition of the ideal $\varepsilon-\mathrm{Fe}_{3} \mathrm{~N}$ phase, there are two nitrogen atoms closest to every iron atom, and nitrogen atoms occupy the one-third of the octahedral intersites of the layered iron atoms. With more octahedral intersites occupied, the ratio of Fe: $\mathrm{N}$ will decrease from 3 to 2. The magnetic moment of $\varepsilon-\mathrm{Fe}_{2 \sim 3} \mathrm{~N}$ phase gradually decreased with the decrement of iron content. For $\mathrm{Fe}_{x} \mathrm{~N}(2 \leqslant x \leqslant 3)$, when $x$ equals 3 , the magnetic moment of each iron atom of $\varepsilon-\mathrm{Fe}_{3} \mathrm{~N}$ can be $2.0 \mu \mathrm{B}$, and while when $x$ equals 2 , the magnetic moment decreases to $0.2 \mu \mathrm{B}$. 


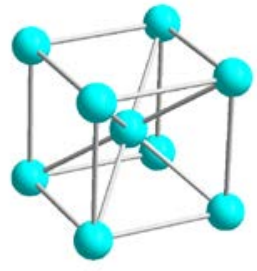

(a)

Fig. 1: The crystal structure of different forms of iron. (a) $\alpha$-Fe, (b) $\gamma$-Fe, (c) $\delta$-Fe, (d) $\varepsilon$-Fe

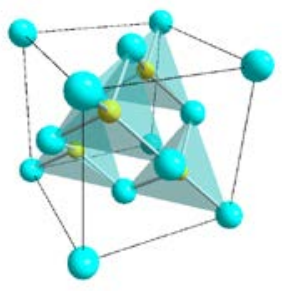

(a)

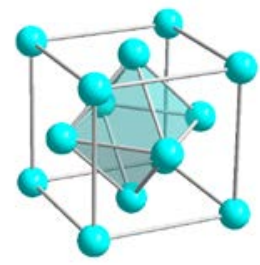

(b)

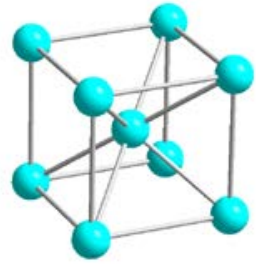

(c)

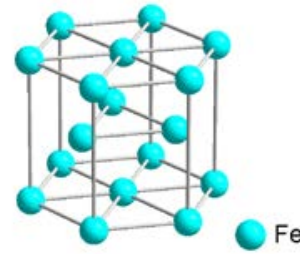

(d)

Fig. 2: The crystal structure of different forms of iron nitrides.

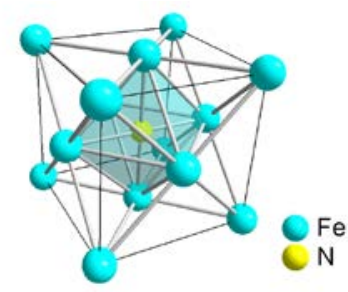

(d)

(a) $\mathrm{FeN}$, (b) $\mathrm{Fe}_{2} \mathrm{~N}$, (c) $\mathrm{Fe}_{2 \sim 3} \mathrm{~N}$, (d) $\mathrm{Fe}_{4} \mathrm{~N}$

$\gamma-\mathrm{Fe}_{4} \mathrm{~N}$ phase (Fig. 2(d)) is composed of a simple cubic lattice which consists of a face-centered cubic array of $\gamma$-Fe atoms and centered nitrogen atoms, where iron atoms form an octahedron structure with nitrogen atoms filling the octahedral interstices. There are two kinds of iron atoms according to the location of the atoms in the crystal structure. The iron atoms occupying the corner site of fcc structure are called $\mathrm{Fe}(\mathrm{I})$, while the iron atoms occupying the center position of the fcc structure are Fe(II). The magnetic moments at Fe(I) and Fe(II) position are $2.98 \mu \mathrm{B}$ and $2.02 \mu \mathrm{B}$ respectively and the lattice constant of $\gamma-\mathrm{Fe}_{4} \mathrm{~N}$ phase is $\mathrm{a}=0.3795 \mathrm{~nm}$. $\gamma-\mathrm{Fe}_{4} \mathrm{~N}$ can remain stable when temperature fall down below $670{ }^{\circ} \mathrm{C}$, while the compounds will transform to $\varepsilon$ phase with the increment of temperature.

\section{Materials Preparation Method}

Iron nitride compounds were prepared by a combination of sol-gel and high-temperature nitridation method. Sol-gel method [8] is the most widely used chemical synthesis method of preparing nano-materials. The sol-gel process usually uses chemical reagent (or dissolve the powder in the solvent) as precursor materials. The raw materials should be mixed evenly to form a stable transparent colloidal solution. Colloidal particles polymerize slowly because of the sol polycondensation, and after that, colloidal solution act as the precursors for an integrated network of either discrete particles or network polymers, which make the solvent fill the rest of the whole network space and end up with the formation of gel-like continuous polymer networks. Finally, the gel converts to the particles we need after heat treatment processes such as drying or sintering.

First of all, we weighed a certain amount of $\mathrm{Fe}\left(\mathrm{NO}_{3}\right)_{3} \cdot 9 \mathrm{H}_{2} \mathrm{O}$ by proportion and dissolved it in 20 $\mathrm{mL}$ of alcohol and stirred it with a magnetic stirrer for 8 hours. Then mixed it with $10 \mathrm{~mL}$ citric acid and put the solution in the drying oven at $60^{\circ} \mathrm{C}$ for 24 hours. Next, the dried gel was calcined at 1000${ }^{\circ} \mathrm{C}$ for $4 \mathrm{~h}$ to obtain iron oxide powder samples. Finally, the samples were nitrided in $\mathrm{NH}_{3}$ flow at different temperature $\left(550,650,750,850,950^{\circ} \mathrm{C}\right)$ for $2 \mathrm{~h}$ to obtain iron nitrides.

\section{Structural Properties}

To confirm the crystal structure of the samples, we use X-ray powder diffraction (XRD). XRD is a rapid analytical technique primarily used for phase identification of a crystalline material [9]. The interaction of the incident rays with the sample produces constructive interference, which is determined by the reflection effect of a series of different lattice planes. 


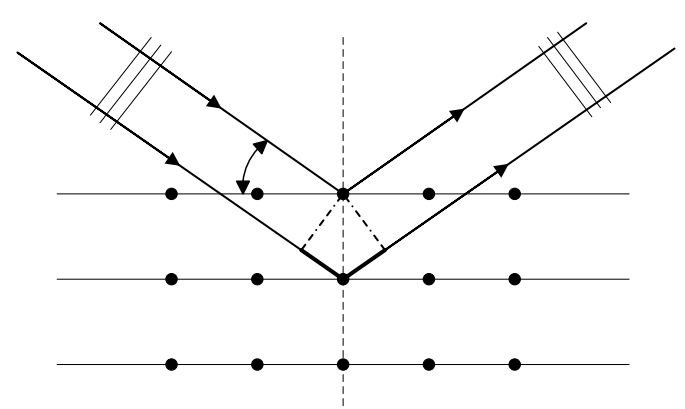

Fig. 3: The principle of XRD.

The principles of XRD can be illustrated by Fig. 3. As shown in Fig. 3, $d$ is the spacing between diffracting planes and $\theta$ is the incident angle. The interaction of the incident rays with the sample produces constructive interference (and a diffracted ray) when Bragg's Law [10] is satisfied as shown in Eq. 1:

$$
2 d \sin \theta=n \lambda
$$

Here $n$ is any integer, and $\lambda$ is the wavelength of the X-beam. This law relates the wavelength of electromagnetic radiation to the diffraction angle and the lattice spacing in a crystalline sample.

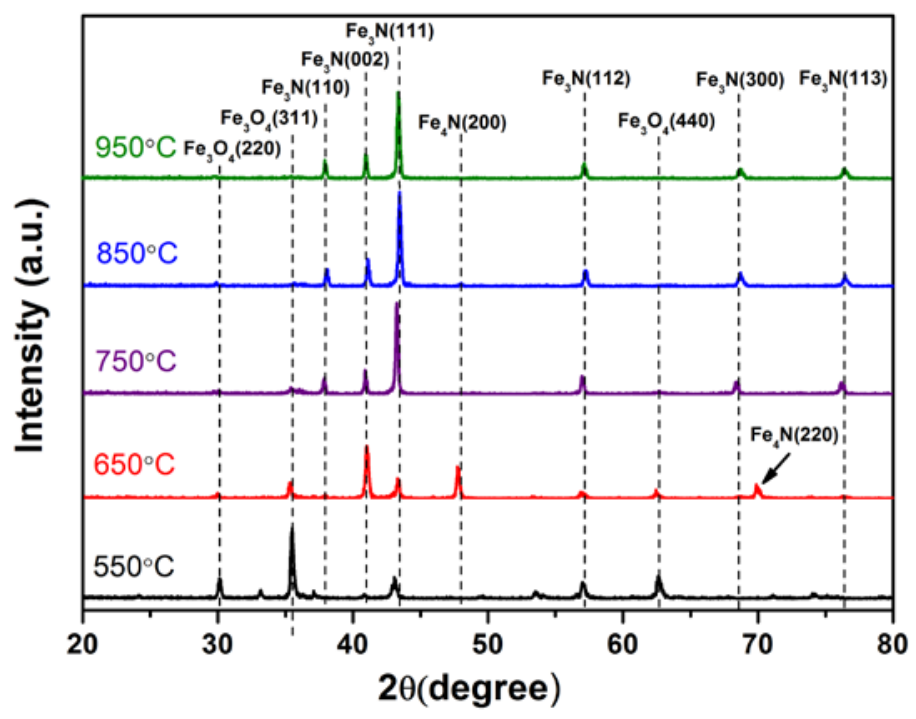

Fig.4 XRD of Fe-N under different nitridation temperature

Fig.4 is the XRD diffraction diagram of Fe-N under different nitridation temperature. $\mathrm{X}$-coordinate is $2 \theta$ with a unit of degree, and the Y-coordinate is intensity with a unit of $a . u$. As shown in the figure, we can find that the diffraction peaks are mainly related to $\mathrm{Fe}_{2} \mathrm{O}_{3}, \mathrm{Fe}_{3} \mathrm{O}_{4}, \mathrm{Fe}_{3} \mathrm{~N}$, and $\mathrm{Fe}_{4} \mathrm{~N}$. When the nitridation temperature is low, such as $550^{\circ} \mathrm{C}$, the diffraction peaks are related to $\varepsilon-\mathrm{Fe}_{3} \mathrm{~N}(101), \gamma-\mathrm{Fe}_{4} \mathrm{~N}(110), \mathrm{Fe}_{3} \mathrm{O}_{4}$ (311) or $\mathrm{Fe}_{2} \mathrm{O}_{3}(110), \varepsilon-\mathrm{Fe}_{3} \mathrm{~N}(002), \varepsilon-\mathrm{Fe}_{3} \mathrm{~N}(111), \varepsilon-\mathrm{Fe}_{3} \mathrm{~N}(112)$, and $\varepsilon-\mathrm{Fe}_{3} \mathrm{~N}$ (202) respectively. When the nitridation temperature is increased to $650^{\circ} \mathrm{C}$, the intensity of the peaks mentioned above is decreased, and some new diffraction peaks are observed such as $\gamma-\mathrm{Fe}_{4} \mathrm{~N}$ (200), $\varepsilon-\mathrm{Fe}_{3} \mathrm{~N}$ (103) and $\gamma-\mathrm{Fe}_{4} \mathrm{~N}$ (220). The intensity of the peaks according to iron oxides is really low when the nitridation temperature is increased to $750^{\circ} \mathrm{C}$ and meanwhile, the peak related to $\varepsilon-\mathrm{Fe}_{3} \mathrm{~N}(110)$ can be observed. When the nitridation temperature comes to $850^{\circ} \mathrm{C}$ and $950^{\circ} \mathrm{C}$, we can only get pure $\varepsilon-\mathrm{Fe}_{3} \mathrm{~N}$.

\section{Summary}

In this work, we prepared iron nitride compounds by a combination of sol-gel method and high-temperature nitridation method. Changing the nitridation temperature, several samples have 
been achieved, and using XRD spectra, the crystal structures have been confirmed. It is found that, when the nitridation temperature is lower, Fe-O and Fe- $\mathrm{N}$ compounds have been achieved, while increasing the nitridation temperatures, only Fe-N compounds have been observed. Especially when the temperature come up to $850{ }^{\circ} \mathrm{C}$, single phase $\varepsilon-\mathrm{Fe}_{3} \mathrm{~N}$ has been observed.

\section{References}

[1] K. H. Jack, The iron-nitrogen system: the crystal structures of $\varepsilon$-phase iron nitrides, J. Acta Cryst. 5 (1952) 404-411.

[2] Akimasa Sakuma, Electronic and magnetic structure of iron nitride, $\mathrm{Fe}_{16} \mathrm{~N}_{2}$, J. Appl Phys. 79 (1996) 5570-5575.

[3] Shen G, Mao HK, Hemley RJ, Duffy TS, Rivers ML, Melting and crystal structure of iron at high pressures and temperatures, Geophys Res Lett. 25(1998), 373-376

[4] Masataka Kano, Takashi Nakagawa, Takao A. Yamamoto, Masahiro Katsura, Magnetism, crystal structure and nitrogen content near the $\epsilon-\zeta$ phase boundary of iron nitrides, J. Alloys Compd. 327 (2001) 43-46

[5] D. Rechenbach, H. Jacobs, Structure determination of $\zeta-\mathrm{Fe}_{2} \mathrm{~N}$ by neutron and synchrotron powder diffraction, J. Alloys Compd. 235(1996) 15-22

[6] Leineweber A, Jacobs H, Huning F, Lueken H, Kockelmann W, Nitrogen ordering and ferromagnetic properties of $\epsilon-\mathrm{Fe}_{3} \mathrm{~N}_{1+} x(0.10 \leq x \leq 0.39)$ and $\epsilon-\mathrm{Fe}_{3}\left(\mathrm{~N}_{0.80} \mathrm{C}_{0.20}\right)_{1.38}$

[7] H Jacobs, D Rechenbach, U Zachwieja, Structure determination of $\gamma^{\prime}-\mathrm{Fe}_{4} \mathrm{~N}$ and $\epsilon-\mathrm{Fe}_{3} \mathrm{~N}$, J. Alloys Compd. 227(1995) 10-17

[8] Larry L. Hench, Jon K. West, The Sol-Gel Process, Chemical Reviews. 90 (1990) 33-72

[9] Klug H P, Alexander L E, X-ray diffraction procedures[M]. Wiley, New York, 1954.

[10]Jauncey G E M, The scattering of x-rays and Bragg's law[J], Proceedings of the National Academy of Sciences. 10(1924) 57-60. 